\title{
Jogos didáticos para o ensino de Astronomia no Ensino Fundamental
}

\author{
Educational games for Astronomy teaching in Elementary Education \\ J. C. Miranda ${ }^{1}$; G. R. Gonzaga ${ }^{1}$; R. C. Costa ${ }^{2}$; C. C. C. Freitas ${ }^{2}$; K. C. Côrtes ${ }^{2}$ \\ ${ }^{1}$ Docente do Departamento de Ciências Exatas, Biológicas e da Terra, Universidade Federal Fluminense, 28.470-000, \\ Santo Antônio de Pádua-RJ, Brasil \\ ${ }^{2}$ Discente do curso de Licenciatura em Ciências Naturais, Universidade Federal Fluminense, 28.470-000, Santo \\ Antônio de Pádua-RJ, Brasil
}

*jeanmiranda@id.uff.br

(Recebido em 20 de agosto de 2015; aceito em 08 de janeiro de 2016)

\begin{abstract}
A Astronomia, apesar de presente em salas de aulas, por vezes, se apresenta como uma série de conteúdos de difícil entendimento. A Olimpíada Brasileira de Astronomia e Astronáutica (OBA), evento realizado desde 1998, foi criada como um importante recurso pedagógico, um instrumento de divulgação que objetiva estimular o interesse dos jovens sobre o tema, atuar como importante auxiliar na aprendizagem, de forma a contribuir para a melhoria do rendimento escolar. O presente trabalho apresenta três jogos didáticos desenvolvidos e aplicados em uma escola pública do Noroeste do Estado do Rio de Janeiro, com vistas à preparação de alunos do Ensino Fundamental para participação na OBA. Os jogos foram confeccionados com materiais de baixo custo e fácil aquisição. Para avaliação da usabilidade dos jogos, a compreensão e a clareza das regras, foi aplicado um questionário composto por oito questões fechadas e uma questão aberta. A análise dos questionários, bem como os resultados obtidos na OBA, indica que os jogos desenvolvidos cumpriram seus objetivos, contribuindo para que o processo de ensino-aprendizagem ocorra de forma divertida, didática e prazerosa. $\mathrm{O}$ trabalho desenvolvido com estas ferramentas didáticas para o estudo de Astronomia produziu um espaço privilegiado de construção e popularização do conhecimento científico com um olhar crítico e construtivo, que, por muitas vezes, é ignorada no trabalho escolar cotidiano.

Palavras-chave: Ensino de Astronomia, Jogos Didáticos, PIBID
\end{abstract}

Astronomy, although present in classrooms, sometimes appears as a series of difficult to understand contents. The Brazilian Olympiad of Astronomy and Astronautics (OBA), an event held since 1998, was created as an important educational resource, a dissemination tool which aims to stimulate the interest of young people on the subject, act as an important aid in learning, in order to contribute to improve school performance. This paper presents three educational games developed and applied in a public school in the Northwest of the State of Rio de Janeiro, with a view to preparing elementary school students to participate in OBA. The games were made with low cost and easy to purchase materials. For evaluation of game usability, understanding and clarity of rules, it applied a questionnaire with eight closed questions and an open question. Analysis of the questionnaires, as well as the results obtained in OBA, indicates that developed games fulfilled their goals, contributing to the process of teaching and learning takes place in a fun, didactic and pleasant way. The work with these teaching tools for astronomy study produced a special area of construction and popularization of scientific knowledge with a critical and constructive look, which, it is often ignored in everyday schoolwork. Keywords: Astronomy Education, Educational Games, PIBID

\section{INTRODUÇÃO}

Astronomia é uma das mais antigas ciências [1], sendo considerada o primeiro conhecimento humano organizado de forma sistemática [2]. É o estudo dos corpos celestes, sua origem, composição, forma e movimentos, dentre outros aspectos. Também tem a finalidade de compreender a estrutura, a formação e o desenvolvimento do Universo [3].

A Astronomia é apontada por Mees e Steffani (2005) [4] como tema motivador do ensino de Física no Ensino Fundamental. É uma disciplina de caráter interdisciplinar, cujos conteúdos estão presentes em salas de aula, nos programas escolares e livros didáticos [5] e integram o eixo "Terra 
e Universo", dos Parâmetros Curriculares Nacionais [6]. Apesar disso, há relatos da dificuldade de compreensão e desconhecimento dos fenômenos astronômicos [1,7]. Por isso, como destacado por Carmino (2012) [8], o desenvolvimento de estratégias de aprendizagem adequadas é um dos grandes desafios no ensino de Astronomia. Soma-se a isso, o fato de que de algumas metodologias, frequentemente usadas nas escolas, reforçam o caráter pouco inovador e pouco criativo, sobretudo quando aplicadas em um contexto pouco significativo e participativo [9]. Para Leite e Hosoume (2007) [10]:

A Astronomia, quando trabalhada no Ensino Fundamental, é desenvolvida de forma tradicional e apenas conceitual, e as representações dos elementos constituintes são abordadas, geralmente, apenas em forma de texto ou de imagens bidimensionais. Temos consciência de que a metodologia de aula não pode mais ser a indicada tradicionalmente nos livros didáticos, pois ela já se revelou ser insuficiente. Devido à natureza abstrata do tema, ele deve, na medida do possível, ser vivenciado de forma prática e concreta. As propostas de ensino deste tema devem indicar a importância do conhecimento dos conceitos construídos intuitivamente, pois eles são a maneira de pensar das pessoas e devem ser incorporados à estrutura e à metodologia das propostas de ensino. [10].

Atividades lúdicas, sobretudo jogos didáticos, podem contribuir significativamente para o processo de construção do conhecimento [11]. Por isso, se apresentam como uma alternativa interessante e relevante para o ensino de Ciências, uma vez que possibilitam abordar os conteúdos de forma dinâmica, divertida e diferenciada. Jogos didáticos devem ser considerados, segundo Orlik (2002) [12], métodos ativos no processo de ensino-aprendizagem, pois motivam e desenvolvem habilidades com aprendizagem significativa [13].

Segundo Almeida (1974) [14], dentre os benefícios que os jogos didáticos proporcionam, destaca-se o desenvolvimento social e psíquico.

... sob o aspecto mental, os jogos visam atingir o desenvolvimento da memória, da atenção, da observação, do raciocínio, da criatividade, da aquisição de hábitos ou virtudes morais, como lealdade, a bondade. Sob o ponto de vista social, os jogos visam a estimular o companheirismo, desenvolver o espírito de cooperação, o senso social e a democratização. [14].

O uso de atividades lúdicas, em sala de aula interfere, também, no aspecto relacional, pois estreita a relação professor-aluno [15]. Além disso, possibilita ao aluno ser sujeito ativo no processo ensino-aprendizagem, em decorrência do aumento do seu interesse. Tal situação é antagônica a verificada quando os alunos estão expostos somente aos métodos tradicionais de ensino, quando são apenas consumidores passivos de informações prontas [16].

Contudo, para Kishimoto (1996) [17] "o jogo não é o fim, mas o eixo que conduz a um conteúdo didático específico, resultando em um empréstimo da ação lúdica para a aquisição de informações" [17].

Souza e Silva (2012) [18] afirmam que o uso de jogos didáticos tem crescido nas últimas décadas como ferramenta complementar a outros recursos educativos, possibilitando aulas mais dinâmicas e interativas, atuando não apenas na transmissão de conhecimentos, mas também como uma forma de compartilhamento destes. Para Miranda (2001) [19], jogos didáticos proporcionam não apenas a possibilidade de interação do aluno com o conteúdo a ele transmitido, mas também colaboram para o desenvolvimento de habilidades como a cognição, afeição, socialização, motivação e criatividade.

O presente trabalho objetiva apresentar jogos didáticos para o ensino de Astronomia, produzidos no âmbito do Subprojeto "PIBID Ciências Naturais - Pádua", desenvolvido na Escola Municipal Escola Viva, em Santo Antônio de Pádua/RJ. É discutida ainda importância dos jogos didáticos na 
preparação de alunos do Ensino Fundamental para participação na Olimpíada Brasileira de Astronomia e Astronáutica e os resultados nela alcançados.

\section{A Olimpíada Brasileira de Astronomia e Astronáutica}

A Olimpíada Brasileira de Astronomia e Astronáutica (OBA) é um evento organizado anualmente pela Sociedade Astronômica Brasileira (SAB) em parceria com a Agência Espacial Brasileira (AEB). A OBA ocorre desde 1998 e tem por objetivo promover a difusão de conhecimentos básicos de Astronomia, Astronáutica e Ciências de forma dinâmica e cooperativa[20], estimular e ampliar o interesse dos jovens por esses campos do conhecimento [21], além contribuir para a melhoria do rendimento escolar.

Podem participar alunos de Ensino Fundamental e Médio, de escolas públicas e privadas. As provas são divididas em quatro níveis: $1^{\circ}$ ao $3^{\circ}$ ano do Ensino Fundamental (nível 1), $4^{\circ}$ e $5^{\circ}$ ano do Ensino Fundamental (nível 2), $6^{\circ}$ ao $9^{\circ}$ ano do Ensino Fundamental (nível 3) e Ensino Médio (nível 4). Os alunos que obtiveram as maiores pontuações são premiados com medalhas e todos os participantes (alunos, professores, diretores e a própria escola) recebem certificados de participação no evento.

\section{O Subprojeto PIBID Ciências Naturais - Pádua e sua atuação na Escola Municipal Escola Viva}

O Programa Institucional de Bolsa de Iniciação à Docência (PIBID) é a maior Política Pública Nacional de Formação Inicial de Professores [22]. O PIBID envolve ações que objetivam suprir a defasagem na formação docente [23], fomentar o reconhecimento e valorização das licenciaturas [24], estimular a prática docente e incentivar o desenvolvimento de ações voltadas à formação dos licenciandos e sua inserção no ambiente escolar [9].

O programa proporciona ao licenciando a oportunidade de vivenciar a prática educacional e o cotidiano escolar, além de incentivar a busca por novas metodologias e estratégias que auxiliem o aprendizado, estimulem a criatividade e a socialização dos educandos e contribuir na formação continuada do professor da educação básica [9].

Desde 2009, a Universidade Federal Fluminense (UFF) participa desta politica pública de formação de professores [22]. O subprojeto "PIBID Ciências Naturais - Pádua", desenvolvido no Instituto do Noroeste Fluminense de Educação Superior (INFES-UFF) teve início em março de 2014. Participam do subprojeto, doze bolsistas de iniciação à docência (alunos do curso de Licenciatura em Ciências Naturais), alunos do segundo segmento do Ensino Fundamental e dois professores supervisores (da escola parceira - Escola Municipal Escola Viva), um professor colaborador e um coordenador de área (docentes do Departamento de Ciências Exatas, Biológicas e da Terra - INFES). Além da inserção do licenciando no cotidiano escolar, o subprojeto objetiva contribuir para a melhoria da qualidade do ensino de Ciências Naturais que é oferecido aos alunos da escola parceira.

Maior escola da rede municipal de ensino de Santo Antônio de Pádua e considerada uma escolamodelo, a Escola Municipal Escola Viva apresenta o maior IDEB da rede municipal de Santo Antônio de Pádua: 5,9. Atende atualmente a 1.200 alunos da Educação Infantil e Ensino Fundamental I e II, dos quais 441 são assistidos pelo "PIBID Ciências Naturais - Pádua".

A Escola Municipal Escola Viva participa da Olimpíada Brasileira de Astronomia e Astronáutica desde 2012, com resultados expressivos. A partir de abril de 2014, a equipe do subprojeto "PIBID Ciências Naturais - Pádua" desenvolveu ações que objetivaram auxiliar os professores regentes na preparação dos alunos para participação na OBA, e o uso de jogos didáticos (desenvolvimento e aplicação) relacionados ao tema foi uma das ferramentas escolhidas para tal. 


\section{MATERIAL E MÉTODOS}

Dentre as ações realizadas com vistas à preparação dos alunos para participação dos alunos na OBA, foram desenvolvidos, aplicados e avaliados três jogos didáticos: "Responde ou Passa Astronomia", "Jogos dos Astros" e "Sorte ou Azar na Astronomia".

Os jogos, que abordam os temas "Origem do Universo", "Corpos Celestes", "Pontos Cardeais", "Estações do Ano", "Solstício e Equinócio", Movimentos da Terra", "Fases da Lua", e "Eclipses", foram produzidos com materiais de baixo custo e fácil aquisição, além do uso de computador, impressora e plastificadora, para padronização e aumento da durabilidade do jogo.

Foi elaborado um questionário (aplicado em todas as turmas que fizeram uso dos jogos confeccionados) com o objetivo de avaliar a usabilidade, a compreensão e a clareza das regras de cada um dos jogos. Para tal, foram desenvolvidas oito questões fechadas com as alternativas "sim", "não" e "pode melhorar", e uma questão aberta para que o aluno expressasse mais livremente as suas observações/opiniões, com relação ao jogo utilizado. Os pontos avaliados foram: 1) as regras do jogo são claras?; 2) as perguntas são objetivas?; 3) o visual do jogo é agradável?; 4) o jogo estimula o aprendizado?; 5) a aula ficou mais interessante com o jogo?; 6) o jogo foi de fácil compreensão?; 7) o tempo do jogo é satisfatório?; 8) as perguntas estão de acordo com a matéria?; e a pergunta aberta, 9) o que você achou do jogo?

A seguir são apresentadas informações relacionadas a cada jogo (componentes do kit, número de participantes e a forma de jogar).

\section{- Responde ou Passa - Astronomia}

O jogo "Responde ou Passa - Astronomia" é composto por setenta e duas cartas (com quatro graus de dificuldade), contendo uma questão com três opções de respostas cada (com a resposta correta sinalizada), um dado de 6 faces para determinação da ordem da jogada e um cronômetro para marcar o tempo que cada jogador tem para responder. Para as cartas, foi definida uma pontuação que varia de -4 a 4 pontos, de acordo com erros e acertos de cada questão, respectivamente. Para o melhor aproveitamento da atividade, a turma deve ser organizada em quatro grupos e o professor atua como mediador.

A ordem do jogo é definida com o lançamento do dado (iniciando o jogo o grupo que obtiver maior número). As cartas são divididas em quatro pilhas de acordo com sua pontuação: uma com 24 cartas (com -1 e +1 ponto) - nível 1, uma com 20 cartas (com - e +2 pontos) - nível 2, uma com 16 cartas (com -3 e +3 pontos) - nível 3, e uma com 12 cartas (com -4 e +4 pontos) - nível 4.

O professor retira uma carta da primeira pilha (nível 1) e lê a questão para o primeiro grupo, iniciando, assim, a primeira rodada e o primeiro nível da partida. Após a leitura da questão, o cronômetro é acionado, e o grupo deve responder antes que o tempo (de 30 segundos) acabe ou passar a vez (sem perder ou ganhar pontos) para o grupo seguinte (que terá o mesmo tempo de resposta).

Se o primeiro grupo acertar a resposta, ganha os pontos da carta, a mesma é descartada e a vez passa para o grupo seguinte. Caso o grupo erre a questão ele contabiliza os pontos negativos da resposta errada, e passa a vez para a equipe seguinte; e assim sucessivamente. Caso a pergunta não seja respondida pelo quarto grupo, ela retorna ao primeiro grupo da rodada, que obrigatoriamente deverá respondê-la. Não havendo mais cartas do nível 1, tem início o nível 2, seguindo a mesma sequência lógica do jogo. Este mesmo procedimento ocorre até que acabem as cartas do nível 4.

A contabilização dos pontos é acumulativa nas rodadas, dando a possibilidade de virada do jogo com as perguntas do nível 4. Após as quatro rodadas, é realizada a contabilidade final dos pontos, e a equipe com maior pontuação é declarada a vencedora. 


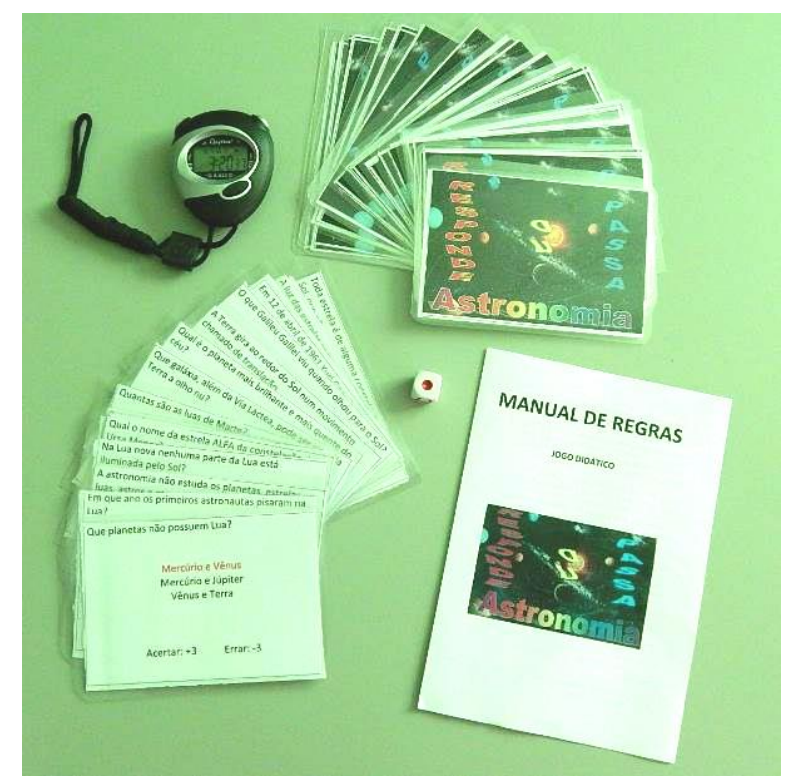

Figura 1: Kit do jogo "Responde ou passa - astronomia

\section{- Jogo dos Astros}

O "Jogo dos Astros" é composto por um tabuleiro com 20 casas, onde os jogadores "percorrem os planetas", tendo como ponto de partida o Sol; 1 dado de seis faces; 70 cartas contendo uma pergunta em cada; e 4 marcadores coloridos ("naves espaciais") representando cada participante (individual ou equipes). Algumas casas do tabuleiro ("casas surpresa") possuem informações "especiais" do tipo "volte uma casa", "fique uma rodada sem jogar", "volte ao Sol (início do jogo) e passe protetor solar", "troca-troca de posições entre as equipes no tabuleiro".

O professor atua como mediador do jogo, que pode ser jogado por equipes ou individualmente. Em caso de formação de equipes, um representante de cada uma delas joga o dado para estabelecer a ordem de participação. A primeira equipe a participar escolhe a cor do seu pino e joga o dado para saber o número de casas a avançar. Antes de avançar com o seu peão, o aluno representante do grupo deverá escolher uma carta-pergunta e a responder, podendo ter o apoio do restante da equipe para dar a resposta; acertando a resposta ele avança o número de casas tirado no dado (podendo cumprir uma missão especial, caso ele caia em alguma das "casas surpresa") e passa a vez ao representante do segundo grupo; se ele errar a resposta, ele permanece no Sol e passa a vez ao representante do segundo grupo, que realizará o mesmo procedimento. Vence o jogo a equipe que atingir primeiro a última casa do tabuleiro (casa 20). 


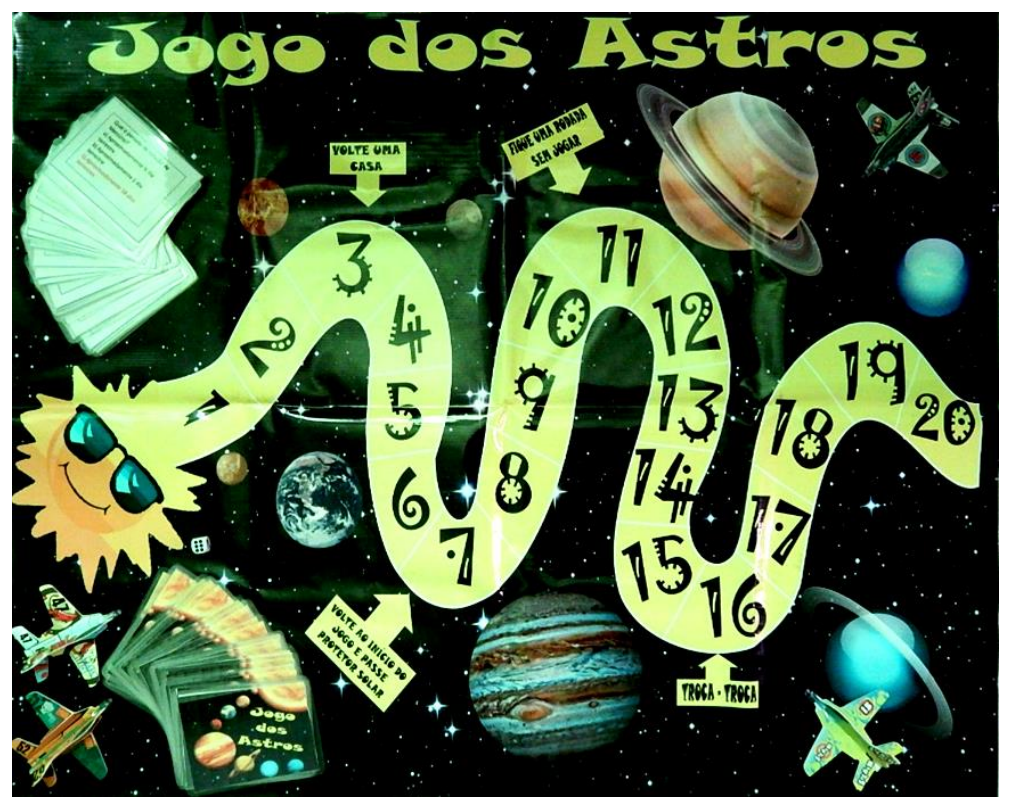

Figura 2: Kit do jogo "Jogo dos Astros"

\section{- Sorte ou Azar na Astronomia}

O jogo didático "Sorte ou azar na Astronomia" constitui-se de 22 cartas de "sorte ou azar", 50 cartas (numeradas) de perguntas (com uma pergunta cada e sem a resposta), uma ficha de respostas (que fica de posse do mediador da partida) e um dado de seis faces (que define a ordem de participação dos jogadores). As regras deste jogo são semelhantes às regras do jogo UNO ${ }^{\circledR}$ e os alunos já devem ter conhecimento prévio do assunto.

Para iniciar o jogo, os participantes (de 3 a 5 jogadores) devem organizar a ordem da partida através do lançamento do dado. O mediador, após a ordenação dos jogadores, deve distribuir 6 cartas de perguntas para cada participante; também deve empilhar na mesa as cartas de "sorte ou azar" e, em separado, no mínimo, 20 cartas de perguntas. O primeiro jogador seleciona uma de suas cartas, lê o número da carta e a pergunta em voz alta para que todos ouçam e a responde. $\mathrm{O}$ mediador, de posse da ficha de respostas, deve conferir se a resposta dada está correta; estando correta, o jogador lê e cumpre o que a carta pede (ao lado de "Certo"), e caso a resposta esteja errada ou o jogador não saiba a resposta, ele deve ler e cumprir o que a carta pede (ao lado de "Errado") ou recorrer a uma carta de "sorte ou azar" (sendo obrigado a cumprir as exigências da carta sem recuar).

Terminada as atividades do primeiro jogador é passada a vez ao segundo, que segue o mesmo procedimento. Todas as cartas lidas devem ser empilhadas no monte de descarte.

Quando um dos jogadores estiver com apenas uma carta na mão ele deve dizer (audível) a palavra ASTRONOMIA, caso contrário deverá comprar uma carta no monte de cartas com pergunta. $\mathrm{O}$ jogo termina quando um dos jogadores esgotar suas cartas da mão. 


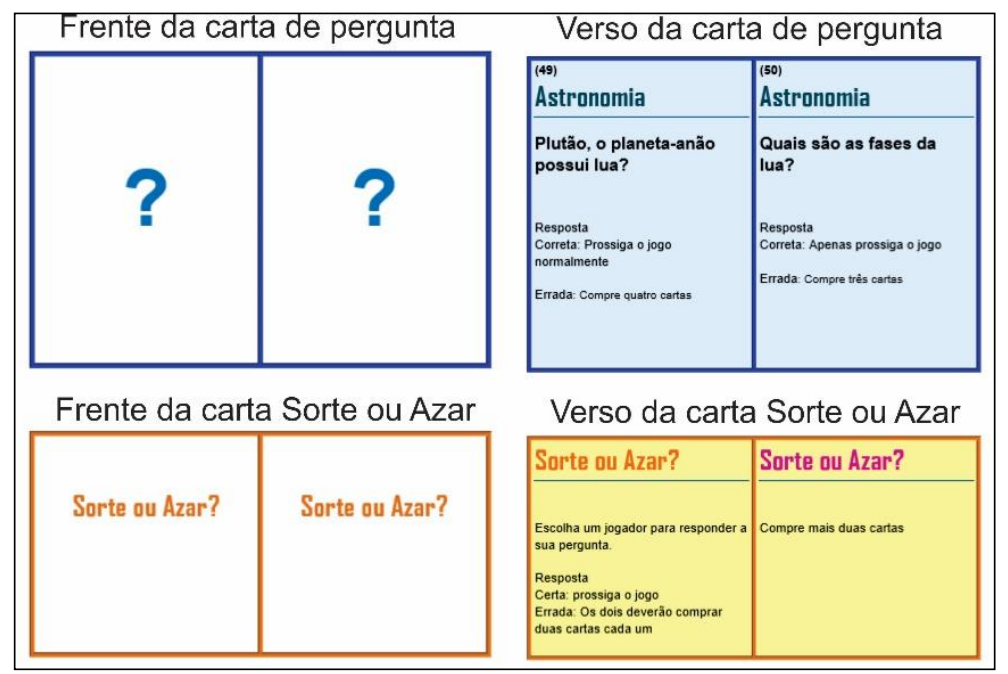

Figura 3: Kit do jogo "Sorte ou Azar na Astronomia”

\section{RESULTADOS E DISCUSSÃO}

Os jogos foram aplicados em momentos diferentes e em turmas diferentes. Isso ocasionou uma diferença no quantitativo de alunos que utilizaram os jogos, como pode ser visto na figura 4; porém, vale ressaltar aqui que todos os alunos que fizeram uso dos jogos desenvolvidos participaram do processo seletivo da OBA e do evento em si.

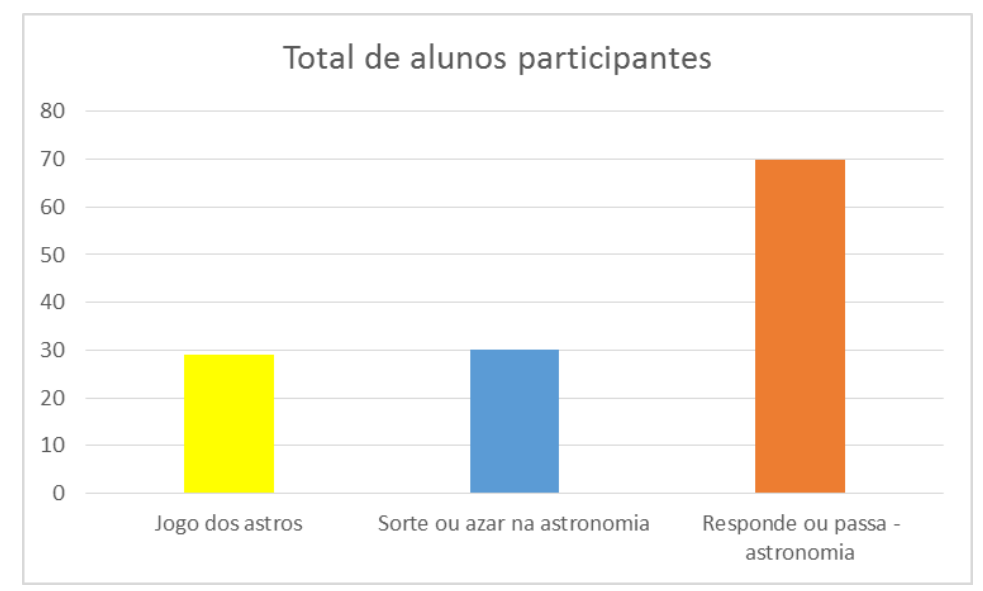

Figura 4: Total de alunos participando das atividades com os jogos desenvolvidos.

O "Jogo dos astros" foi utilizado por uma turma de sétimo ano (turma 701), o jogo "Sorte ou azar na Astronomia" foi utilizado por uma turma de oitavo ano (turma 801), e o jogo "Responde ou passa - Astronomia" foi utilizado por duas turmas de sexto ano (turmas 600 e 603) e uma de oitavo ano (turma 800).

Como mencionado anteriormente, além da utilização dos jogos nas turmas acima apresentadas, foi realizada uma sondagem de opinião através de aplicação de questionário aos alunos participantes dos jogos desenvolvidos. Os resultados positivos para os três jogos desenvolvidos e aplicados podem ser observados na figura 5. 


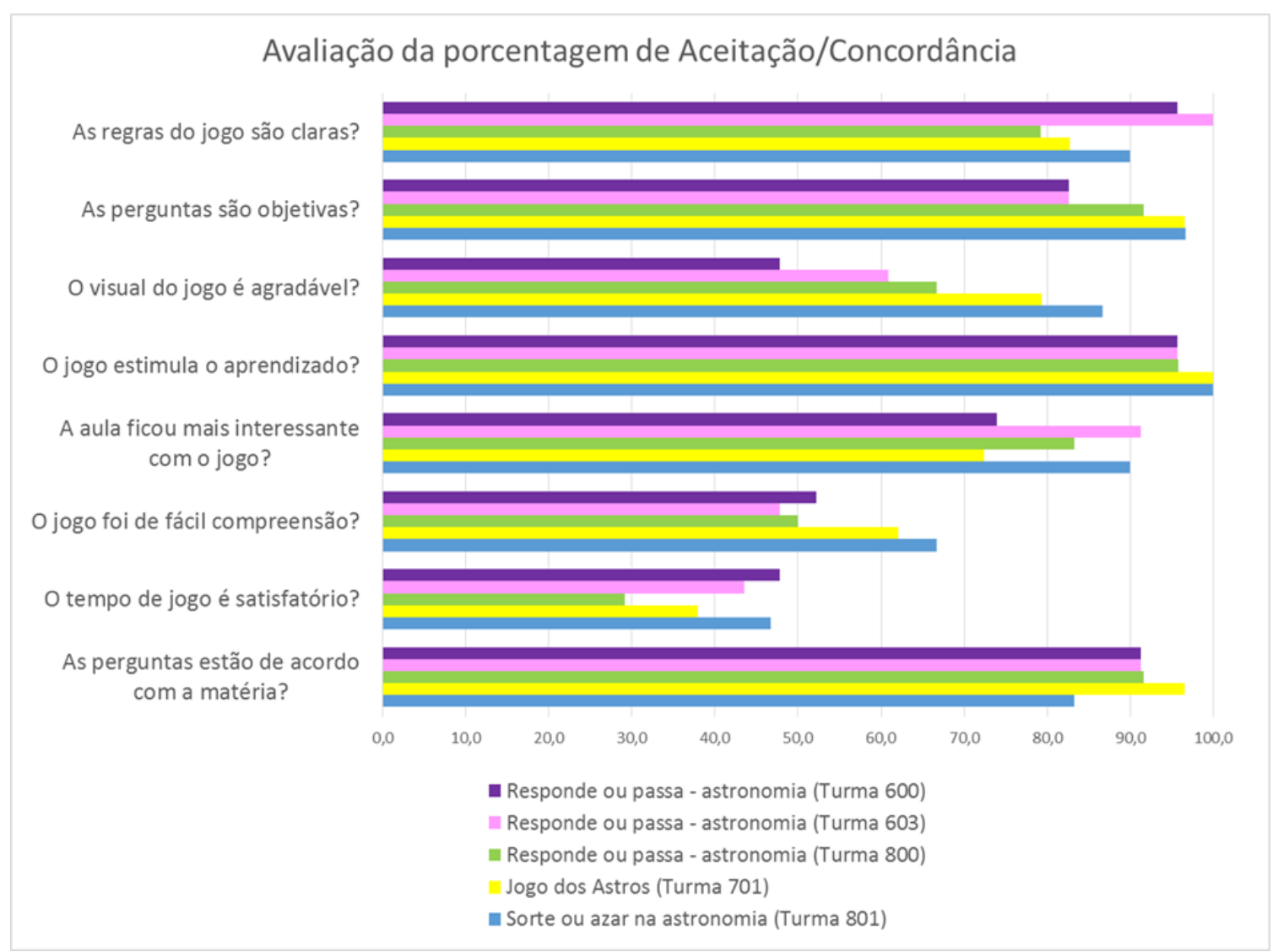

Figura 5: Resultados afirmativos para os questionários aplicados nos três jogos desenvolvidos.

Conforme pode ser observado na figura 5 , os jogos desenvolvidos possuem grande aceitação pela maioria dos alunos participantes. Observando item a item investigado, dos três jogos avaliados pelas cinco turmas, pode-se verificar que:

(i) A clareza das regras é apontada por $89,1 \%$ do total de alunos participantes;

(ii) $90,7 \%$ dos alunos afirmam que as perguntas dos jogos foram objetivas;

(iii) 69,8\% dos alunos acharam o visual dos jogos agradável;

(iv) Quanto ao estímulo proporcionado pelos jogos, 97,7\% dos alunos afirmaram se sentirem mais estimulados com o uso das atividades;

(v) Apesar da alta porcentagem de alunos estimulados, apenas $82,2 \%$ dos alunos acharam que a aula se tornou mais interessante;

(vi) Apenas 56,6\% dos alunos compreenderam facilmente os jogos utilizados. Esse baixo resultado pode ser atribuído ao jogo "Responde ou Passa - Astronomia", e dois fatores devem ser levados em consideração, o primeiro é este jogo ter sido aplicado em duas turmas de sexto ano juntamente com uma de oitavo (Abreu e colaboradores (1998)[25] afirmam que o interesse por jogo de regras aumenta com a idade, e a diferença de faixa etária das turmas no qual este jogo foi aplicado pode ter influenciado negativamente o resultado deste item), e o segundo fator e a maior complexidade das regras, da forma de apresentação e do conteúdo deste jogo se comparado aos outros (pois neste jogo o próprio aluno escolhe e manipula suas cartas de perguntas sem respostas, estando estas de posse do mediador; essa dinâmica não é comum em jogos cotidianos e pode ter influenciado negativamente o resultado deste quesito);

(vii) Apenas 41,1\% dos alunos participantes consideraram satisfatório o tempo das partidas. $\mathrm{E}$ apesar desse percentual ser baixo este não é considerado um resultado ruim, pois os alunos afirmavam que gostaria de jogar mais tempo (e mais de uma partida), pois estavam 
gostando da dinâmica da atividade e da proposta da mesma, e que por isso alguns pontuaram que o tempo não era satisfatório;

(viii) Com relação ao jogo se adequar ao conteúdo estudado, 90,7\% dos alunos participantes afirma que os jogos abordam os assuntos tratados em sala de aula, corroborando com a classificação dos jogos como sendo de fixação de conceitos [26] e exercício e prática, ou jogo de regras, dentro da classificação proposta por Piaget (1971) [27].

Fazendo uma observação da aceitação/concordância média (baseada no quantitativo das respostas positivas dos questionários aplicados nas cinco turmas participantes da pesquisa) dos três jogos desenvolvidos, o jogo que teve maiores resultados positivos foi o jogo "Sorte ou Azar na Astronomia", com a aceitação média de 82,5\%, seguido pelo "Jogo dos Astros" com 78,4\% de aceitação média, e, por fim, pelo "Responde ou Passa - Astronomia" com aceitação média de $74,5 \%$.

Esse resultado quantitativo é reforçado pela análise qualitativa das respostas da nona pergunta (aberta) do questionário aplicado. Esta nona pergunta se refere à opinião do aluno com relação ao jogo. É uma pergunta aberta na qual o aluno pode se expressar livremente escrevendo sua opinião. Para o jogo "Sorte ou Azar na Astronomia", 29 alunos (dos 30 participantes) afirmaram que o jogo era 'legal/bom/divertido', e apenas 1 afirmou que o jogo 'podia melhorar'. Para o "Jogo dos Astros", dos 29 alunos participantes, 27 afirmam que o jogo é 'muito legal/bom/divertido/interessante', 1 aluno respondeu que achou o jogo 'chato' e 1 aluno respondeu que achou o jogo "mais ou menos'. Para o "Responde ou Passa - Astronomia", dos 70 alunos participantes, 5 alunos acharam o jogo 'chato' e 65 alunos afirmaram que o jogo é 'muito útil/divertido/interessante/estimulante/divertido/legal'.

A influência da aplicação destes jogos, dentro desta temática, pôde ser sentida por toda a comunidade escolar, não apenas no desempenho acadêmico dos alunos envolvidos (que passaram a enxergar as Ciências e a Astronomia de forma diferenciada), mas também nos resultados da OBA de 2014 (conquista de 21 medalhas, sendo 7 de prata e 14 de bronze).

Um dado a ser destacado é o aumento significativo no número de alunos participantes da OBA. Em 2012 foram 303 alunos; em 2013 esse número aumentou para 418; e em 2014, após a atuação dos bolsistas do "PIBID Ciências Naturais - Pádua" (com suas propostas de atividades e jogos didático-pedagógicos, como os três jogos apresentados neste artigo), o número de alunos chegou a 708 [20].

Esse aumento foi decorrente da atuação de bolsistas do PIBID Ciências Naturais que, através da aplicação de ferramentas não tradicionais na preparação dos alunos, despertou interesse dos alunos e professores em participar do projeto [20].

\section{CONCLUSÃO}

O ensino da Astronomia no Ensino Fundamental é considerado por muitos professores e pesquisadores como um campo importante para o desenvolvimento (integral) dos alunos em formação, para entenderem melhor a formação do Universo e conseguirem interligar várias áreas do conhecimento. Uma pesquisa desenvolvida em âmbito nacional por Martinez e colaboradores (2011) [28] com professores de Ciências que participam da OBA aponta que $81 \%$ destes professores acham o ensino de Astronomia importante e que 96\% afirmam que os alunos da educação básica (ensinos fundamental e médio) devem aprender Astronomia na escola (este resultado inclui até mesmo alguns dos professores que disseram na pesquisa que o ensino de Astronomia não é extremamente essencial).

Essa mesma pesquisa desenvolvida por Martinez e colaboradores (2011) [28] também aponta que $77 \%$ destes professores participantes da pesquisa não estudou Astronomia em sua formação. Esse cenário permite a maior exploração do uso de atividades lúdicas didático-pedagógicas 
complementares, como a aplicação de jogos didáticos, voltadas para o ensino de Astronomia, a fim de suprir carências e necessidades com relação a esta temática.

Os jogos didáticos são ferramentas educacionais que contribuem não apenas para a aquisição de conhecimento e informações, mas também para o desenvolvimento físico, intelectual, social e cognitivo do aluno [29; 30] por gerar a denominada "zona de conhecimento proximal" [31]. O envolvimento com os jogos didáticos desperta no aprendiz o interesse, o que o torna sujeito ativo no processo de ensino-aprendizagem [32].

Têm se tornado atividades didáticas essenciais neste novo cenário educacional, onde a evolução do processo de ensino-aprendizagem teve início tardio frente a evolução tecnológica, por exemplo.

Os três jogos desenvolvidos são classificados por Grando (1995 apud Lopes e Carneiro, 2009) [26] como "jogo pedagógico de fixação de conceitos", uma vez que não há uma construção dinâmica ativa do conhecimento e que o aluno precisa ter esse conhecimento prévio sobre conteúdo para realizar com êxito a proposta dos jogos.

De acordo com os resultados da análise dos jogos pelos alunos, podemos afirmar que os jogos cumpriram com seus objetivos, de fortalecer o processo de ensino-aprendizagem de forma divertida, didática e prazerosa. Os alunos avaliaram os jogos desenvolvidos como ferramentas valiosas no aprendizado.

Além disso, o resultado positivo do uso desta ferramenta também pôde ser verificado nos resultados da OBA realizada em 2014 (no qual houve participação ativa dos bolsistas do subprojeto PIBID Ciências Naturais - Pádua, com os jogos desenvolvidos). A influência do uso dos jogos desenvolvidos pelos bolsistas refletiu no número de professores interessados em participar da OBA (pois os professores também foram influenciados positivamente com o uso de outras ferramentas no processo de ensino-aprendizagem, identificando fatores positivos no mesmo, como aumento do interesse e da motivação dos alunos nas aulas e o aumento do desempenho acadêmico), no número de alunos classificados para participar da OBA (com um aumento de 290 alunos em relação ao ano anterior), e o número de medalhas obtidas ao final da OBA.

Nossos dados corroboram a afirmação de Souza e colaboradores (2015) [20] de que as ações desenvolvidas no âmbito do Subprojeto PIBID Ciências Naturais - Pádua contribuíram na complementação e fixação dos conteúdos trabalhados em sala de aula, auxiliando na construção de uma aprendizagem significativa, uma vez que trouxeram um olhar diferenciado na abordagem dos conteúdos, com destaque para a participação do aluno na construção do conhecimento.

\section{AGRADECIMENTOS}

Aos bolsistas do PIBID Ciências Naturais - Pádua (INFES - UFF) pela colaboração, à Escola Municipal Escola Viva pela parceria e à CAPES pelo apoio financeiro ao projeto.

\section{REFERÊNCIAS BIBLIOGRÁFICAS}

1. Bretones OS. Jogos didáticos para o ensino de Astronomia. São Paulo: Átomo, 2014. 128 p.

2. Mourão RRF. Dicionário enciclopédico de Astronomia e Astronáutica. Rio de Janeiro: Lexikon Editora Digital, 2008. 961 p.

3. Pellenz D, Tisott JC. Atividades experimentais em Astronomia para a construção do conhecimento através de uma proposta interdisciplinar e contextualizada. Scientia cum Industria, 2014, 2(2): 73 76.

4. Mees AA, Steffani MH. Astronomia: motivação para o ensino de Física na $8^{\mathrm{a}}$ série. Anais do XVI Simpósio Nacional de Ensino de Física - SNEF, 2005. Disponível em: http://www.sbf1.sbfisica.org.br/eventos/snef/xvi/cd/resumos/t0105-1.pdf. Acesso em: 01 de agosto de 2015.

5. Bretones, OS, Compiani M. Saindo da sala de aula para observar os planetas e criar uma nova prática pedagógica. Experiências em Ensino de Ciências 2012, 7(3): 36-52.

6. Brasil. Ministério da Educação. Secretaria de Educação Fundamental. Parâmetros Curriculares Nacionais: Ciências Naturais. ( $3^{\circ}$ e $4^{\circ}$ ciclos do Ensino Fundamental). Brasília: MEC, 1998. 138 p. 
7. Silva T, Barroso MF. Fenômenos Astronômicos e Ensino a Distância: Produção e Avaliação de Materiais Didáticos. In: XI Encontro de Pesquisa em Ensino de Física, Sociedade Brasileira de Física, 2008. p. 1-12.

8. Carmino N. Aprender Astronomia jugando em uma plaza. Revista Latino-Americana de Educação em Astronomia 2012, 14: 36-59.

9. Miranda JC, Mello RB. Implementação e ações do PIBID - Ciências Naturais no Noroeste do Estado do Rio de Janeiro. In: Anais do III Encontro Regional de Ensino de Biologia - Regional 4 (MG, GO, TO, DF), Universidade Federal de Juiz de Fora, 2015. p. 1-8.

10. Leite C, Hosoume Y. Os professores de ciências e suas formas de pensar a astronomia. Revista Latino-Americana de Educação em Astronomia (RELEA), Limeira, n. 4, p.47-68. 2007.

11. Santos CA. Jogos e atividades lúdicas na alfabetização. Rio de janeiro: Sprint, 1998. 154 p.

12. Orlik E. Química: métodos activos de enseñanza y aprendizaje. México: Iberoamérica, 2002. 358 p.

13. Ausubel DP, Novak JD, Hanesian H. Educational psychology: a cognitive view. New York: Holt Rinehart and Winston, 1978. 752 p.

14. Almeida PN. Dinâmica lúdica: técnicas e jogos pedagógicos. São Paulo: Editora Loyola, 1974. 152 p.

15. Jesus IS, Nogueira FB, Silva EE, Santos, FR. O Jogo "O elemento que liga" como recurso didático no ensino de ligações químicas. Scientia Plena 2013, 9(7b): 1-6.

16. Teixeira MC, Rocha LJP, Silva VS. Lúdico: Um Espaço para a Formação de Identidades. In: III Simpósio de Formação de Professores, Rio de Janeiro, 2005, p. 1-14.

17. Kishimoto TM. Jogo, brinquedo, brincadeira e a educação. São Paulo: Cortez, 1996. 183 p.

18. Souza HYS, Silva CKO. Dados Orgânicos: Jogo Didático no Ensino de Química. HOLOS 2012, 28(3): 107-121 http://dx.doi.org/10.15628/holos.2012.737

19. Miranda S. No Fascínio do jogo, a alegria de aprender. Ciência Hoje 2001, 28(168): 64-66.

20. Souza DG, Santos CAC, Miranda JC. A atuação do PIBID na preparação de alunos para participação em Olimpíadas Escolares. In: Anais do III Encontro Regional de Ensino de Biologia - Regional 4 (MG, GO, TO, DF), Universidade Federal de Juiz de Fora, 2015. p. 1 - 8.

21. Villas da Rocha JF, Canalle JBG, Medeiros JR, Souza CAW, Silva AR, Lavouras DF, Dottori HA, Maia MAG, Poppe PCR, Martins RV. V Olimpíada Brasileira de Astronomia. Caderno Brasileiro de Ensino de Física 2003, 20(2): 257-270.

22. Souza FS, Miranda JC. As concepções do PIBID de Matemática e Ciências Naturais no INFESUFF. In: III Colóquio Brasil-Colômbia: Políticas Públicas e Direito à Educação, Universidade Federal Fluminense, 2014, p. 1-12.

23. Scheibe L. Valorização e formação dos professores para a educação básica: questões desafiadoras para um novo plano nacional de educação. Educação \& Sociedade 2010, 31 (112): 981- 1000.

24. Paredes GGO, Guimarães OM. Compreensões e significados sobre o PIBID para a melhoria da formação de professores de biologia, física e química. Química Nova na Escola, 2012, 34: 266-277.

25. Abreu SN, Ortega AC; Sachi R, Cavarra C, Almeida LIR, Zanotti SV. Tipificação e Estereotipia da preferência Lúdica. In: II Congresso Brasileiro de Psicologia do Desenvolvimento. Gramado/RS. Anais do II Congresso Brasileiro de Psicologia do Desenvolvimeto, 1998. p. 48-49

26. Lopes OR, Carneiro CDR. O jogo "Ciclo das Rochas" para ensino de Geociências. Revista Brasileira de Geociências 2009, 39(1): 30-41.

27. Piaget, J. A formação do símbolo na criança: imitação, jogo e sonho imagem e representação. 3.ed. Rio de Janeiro: Zahar, 1971. 370 p.

28. Martinez IG, Ferreira IS, Brito PE de. Kit - Astronomia: um recurso didático para inserção das Ciências no Ensino Básico. In: VIII Encontro Nacional de Pesquisa em Educação em Ciências. Universidade Estadual de Campinas. Campinas/SP, 2011, p. Anais do VIII Encontro Nacional de Pesquisa em Educação em Ciências. Resumo 724-1. Disponível em: < http://www.nutes.ufrj.br/abrapec/viiienpec/resumos/R0724-1.pdf>

29. Mafra SRC. O Lúdico e o desenvolvimento da criança deficiente intelectual. São Paulo. Secretaria de Estado da Educação / Superintendência da Educação / Diretoria de Políticas e Programas Educacionais / Programa de Desenvolvimento Educacional. 2008. 52 p. Disponível em: <http://www.diaadiaeducacao.pr.gov.br/portals/pde/arquivos/2444-6.pdf >.

30. Kishimoto TM. O Jogo e a educação infantil. São Paulo: Pioneira Thomson Learning, 2003. 63 p.

31. Vygotsky L. A formação social da mente. São Paulo: Martins Fontes, 2000. 224 p.

32. Lopes M da G. Jogos na Educação: criar, fazer, jogar. São Paulo: Cortez, 2001. 192 p. 